\title{
Ensino da Arte e do Design no Brasil: unidos antes do Modernismo ${ }^{1}$
}

\author{
Art and Design teaching in Brazil: united before Modernism
}

\author{
Ana Mae Barbosai \\ Universidade de Anhembi Morumbi \\ O oposto do design é o caos. \\ Buckminster Fuller
}

\begin{abstract}
Resumo
Este texto procura demonstrar o divórcio que se estabeleceu entre o Ensino da Arte praticado na Academia Imperial de Belas Artes, depois da Republica nomeada Escola Nacional de Belas Artes e o Ensino do Desenho proposto pelos liberais para a escola primária e secundaria publicas. Enquanto as escolas particulares para meninos e meninas ricas se mantiveram atadas a copias de paisagens europeias e retratos, na escola pública se praticava a Educação para iniciação ao Design, baseada em Walter Smith através dos projetos de Rui (Ruy) Barbosa. A preocupação política do ensino do desenho para preparar para o trabalho foi a partir do primeiro surto industrial no Brasil uma constante até o modernismo.
\end{abstract}

Palavras chave

Ensino do Desenho; Walter Smith; Rui Barbosa

\section{Abstract}

This paper seeks to demonstrate the divorce established between the Art Education practiced in the Imperial Academy of Fine Arts, after the Republic, named National School of Fine Arts and the Design Teaching proposed by liberals for primary and secondary public schools. While private schools for rich boys and girls remained tied to copies of European landscapes and portraits, in public schools, art education was practiced towards an initiation to Design, based on Walter Smith ideas through Rui (Ruy) Barbosa's projects. The political concern of teaching design for labor purposes was a constant from the first industrial boom in Brazil until modernism.

\section{Keyword}

Design Education; Walter Smith; Rui Barbosa

O início do ensino da arte e do design no Brasil está marcado pela dependência cultural. O primeiro produto cultural brasileiro de origem erudita foi o Barroco. Trazido

\footnotetext{
${ }^{1}$ Este texto é um recorte e colagem dos muitos textos que escrevi em defesa do Ensino da Arte relacionado com o Design no Ensino Médio no Brasil.
}

Revista Digital do LAV - Santa Maria - vol. 8, n. 2, p. 143 - 159. - mai./ago. 2015 ISSN 1983 - 7348 http://dx.doi.org/10.5902/1983734819869 
de Portugal recebeu através da criação popular características que podem ser consideradas de cunho nacional. Os artistas e artesãos brasileiros criaram um barroco com distinções formais em relação ao Barroco europeu. O ensino da arte barroca tinha lugar nas oficinas através do fazer sob a orientação do mestre. A atividade de Manoel Dias de Oliveira (1764-1837), como professor da aula régia de desenho e figura em 1800, já introduzindo ao código neoclássico aprendido por ele na Europa, não chegou a interferir, nem de longe a abalar a corrente barroco-rococó dominante nas oficinas da Bahia, Minas Gerais e Pernambuco.

Estas oficinas eram a única educação popular na época. A primeira institucionalização sistemática do ensino de arte foi a Missão Francesa, e um dos poucos modelos com atualidade no país de origem no momento de sua importação para o Brasil. Quase sempre os modelos estrangeiros foram tomados de empréstimo numa forma já enfraquecida e desgastada.

\section{Atualidade da Missão Francesa}

Os integrantes da Missão Francesa que aqui chegaram em 1816 eram membros do Instituto de França que havia sido aberto em 1795 para substituir as velhas academias de arte suprimidas pela Revolução Francesa. Sob a supervisão e a influência de David (1748-1825), o mestre do Neoclássico, o Instituto de França logo alcançou reputação superior à École des Beaux-Arts. Influenciou as escolas de toda a Europa por ser metodologicamente a instituição mais moderna de seu tempo.

Por outro lado, o neoclássico, através do qual se expressavam os artistas da Missão Francesa quando para cá vieram organizar a nossa primeira escola de arte, era o estilo de vanguarda naquele tempo na Europa.

Todavia, os planos apresentados por Le Breton (1760-1819), chefe da Missão Francesa, para a Escola de Ciências. Artes e Ofícios, criada por decreto de D. João VI em 1816, eram de cunho mais popular que a orientação seguida no Instituto de França onde ele ensinava e apontavam para a formação em desenho industrial que foi a primeira designação do que se transformou depois em ensino da Arte e do Design nas escolas, principalmente na Inglaterra.

Revista Digital do LAV - Santa Maria - vol. 8, n. 2, p. 143 - 159. - mai./ago. 2015 ISSN 1983 - 7348 http://dx.doi.org/10.5902/1983734819869 
O projeto repetia os mais atuais modelos de ensino de atividades artísticas ligadas a ofícios mecânicos empregados na França por Bachelier em sua École Royale Gratuite de Dessin, que existe até hoje com o nome de École Nationale des Arts Décoratifs.

Bachelier, que era mestre de decoração em porcelana da fábrica de Sèvres, conseguiu combinar e conciliar em sua escola (1767) métodos e objetivos de ensino de arte comuns às corporações e às academias. Ele contornou a tradicional luta entre artistas e artífices, conseguindo apoio das academias para o seu trabalho pedagógico, exigindo, por exemplo, que os mestres de desenho de sua escola tivessem obtido prêmios da academia.

A experiência de Bachelier, muito comentada e aplaudida na Europa, levou países como a Alemanha e a Áustria a introduzirem o desenho criativo no treinamento das escolas para trabalhadores manuais e as escolas de Belas Artes a considerarem importante o ensino da geometria.

Era este casamento feliz entre as Belas Artes e as indústrias que Le Breton pretendia repetir no Brasil. Pelos planos de Le Breton nossa escola de arte seria uma entidade que não perderia de vista o equilíbrio entre educação popular e educação da burguesia.

Entretanto, quando aquela escola começou a funcionar em 1826 sob o nome de Academia Imperial das Belas Artes, não só o nome havia sido trocado, mas principalmente sua perspectiva de atuação educacional, tornando-se o lugar de convergência de uma elite cultural que se formava no país para movimentar a corte, dificultando, assim, o acesso das camadas populares à produção artística. A Academia Imperial das Belas-Artes inaugurou a ambigüidade na qual até hoje se debate a educação brasileira - isto é, o dilema entre educação de elite e educação popular. Na área específica de educação artística incorporou o dilema já instaurado na Europa entre arte como criação e técnica.

Revista Digital do LAV - Santa Maria - vol. 8, n. 2, p. 143 - 159. - mai./ago. 2015 ISSN 1983 - 7348 http://dx.doi.org/10.5902/1983734819869 
Em 1855, Araújo Porto Alegre (1806-79), baseado no ideário romântico, pretendeu revigorar a educação elitista que vinha tendo lugar na Academia Imperial das BelasArtes através do contato com o povo. Pretendia sua reforma conjugar no mesmo estabelecimento escolar duas classes de alunos, o artífice e o artista, freqüentando juntos as mesmas disciplinas básicas. A formação do artista era alargada com outras disciplinas de caráter teórico, especializando-se o artífice nas aplicações do desenho e na prática mecânica.

A permanência dos velhos métodos e de uma linguagem sofisticada fez com que a procura popular por esses cursos fosse quase nula, assim como foi quase nula também a matrícula nos cursos noturnos para a formação de artífices criados em 1860 na academia. Nestes últimos, a simplificação curricular era quase pejorativa. Em ambos os casos a inclusão da formação do artífice naquela instituição era uma espécie de concessão da elite à classe obreira e por isso destinada ao fracasso.

Já o Liceu de Artes e Ofícios de Bethencourt da Silva (1831-1928), criado em 1856 no Rio de Janeiro, mereceu de pronto um alto grau de confiança das classes menos favorecidas, como atestou o grande número de matrículas já no primeiro ano de funcionamento. Coube aos liceus de artes e ofícios, criados na maioria dos Estados, com pequenas variáveis do modelo do Liceu de Bethencourt da Silva, a tarefa de formar não só o artífice, mas os artistas que provinham das classes operárias.

Até 1870 pouco se contestou o modelo de ensino da arte da Academia Imperial das Belas-Artes, que foi em parte utilizado pela escola secundária.

Nas escolas secundárias particulares para meninas elas aprendiam a copiar retratos e paisagens, o bordado e a tocar piano, nas escolas particulares meninos imperava a cópia de retratos de pessoas importantes e santos e a cópia de estampas, em geral européias, representando paisagens desconhecidas aos nossos olhos acostumados ao meio ambiente tropical.

Revista Digital do LAV - Santa Maria - vol. 8, n. 2, p. 143 - 159. - mai./ago. 2015 ISSN 1983 - 7348 http://dx.doi.org/10.5902/1983734819869 
Estas paisagens levavam os alunos a valorar esteticamente a natureza européia e depreciar a nossa pela rudeza contrastante.

É interessante notar que no século XIX poucos países do Novo Mundo instituíram o ensino da arte para meninos nas escolas de elite. O mais comum é que a arte tivesse lugar apenas nas escolas de meninas de alta classe.

No Brasil isto ocorreu porque a elite brasileira esteve no período colonial mais ligada aos modelos aristocráticos do que aos modelos burgueses como nos outros países americanos.

Segundo o modelo aristocrático, arte era indispensável na formação dos príncipes. D. João VI deu o exemplo quanto contratou Pallière (1823-87) para ensinar desenho aos príncipes.

Seguindo este padrão, a arte foi incluída ela primeira vez em 1811 no currículo do colégio do padre Felisberto Antônio Figueiredo de Moura, uma escola para rapazes no Rio de Janeiro que determinou o modelo de educação para meninos de alta classe na época.

O conteúdo e a função da arte nestas escolas foram sugeridos por Raul Pompéia no seu livro $O$ ateneu:

(...) A apresentação da exposição anual era o objetivo das aulas de arte e se constituía numa espécie de símbolo de distinção para a escola. Raul Pompéia, que foi desenhista e romancista, nos comunica através de sua linguagem sensível o clima de uma exposição escolar no século XIX, numa escola de meninos de classe alta. Para a exposição dos desenhos foram retiradas as carteiras da sala de estudo, forradas de metim escuro as paredes e os grandes armários. Sobre este fundo, alfinetaramse as folhas de Carson, manchadas a lápis pelo sombreado das figuras, das paisagens, pregaram-se nas molduras de friso de ouro, os trabalhos reputados dignos desta nobilitação. Eu fizera o meu sucessinho no desenho, e a garatuja evoluíra no meu traço, de modo a merecer econômicos. A princípio, o bosquejo simples, linear experiência da mão; depois, os esbatimentos de

Revista Digital do LAV - Santa Maria - vol. 8, n. 2, p. 143 - 159. - mai./ago. 2015 ISSN 1983 - 7348 http://dx.doi.org/10.5902/1983734819869 
tons que consegui logo com um matiz de nuvem; depois, as vistas de campo, folhagem rendilhada em bicos, pardieiros em demolição pitoresca da escola francesa, como ruínas de pau pobre, armadas para os artistas. Depois de muito moinho velho, muita vivenda de palha, muito casarão deslombado, mostrando misérias como um mendigo, muita pirâmide de torre aldeã esboçada nos últimos planos, muita figurinha vaga de camponesa, lenço em triângulo pelas costas, rotundas ancas, saias grossas em pregas, sapatões em curva, passei ao desenho das grandes cópias, pedaços de rosto humano, cabeças completas, cabeças de corcel; cheguei a ousadia de copiar com toda a magnificência das sedas, toda a graça forte do movimento, uma cabra de Tibete! Depois da distinção do curso primário, foi esta cabra o meu maior orgulho. Retocada pelo professor, que tinha o bom gosto de fazer no desenho tudo quanto não faziam os discípulos, a cabra tibetana, meio metro de altura, era aproximadamente obra-prima. Ufanava-me do trabalho. Não quis a sorte que me alegrasse por muito. Negaram-me a bela cabra a moldura dos bons trabalhos; ainda em cima - considerem o desespero! Exatamente no dia da exposição, de manhã, fui encontrá-la borrada por uma cruz de tinta, larga, de alto a baixo, que a mão benigna de um desconhecido traçara. Sem pensar mais nada, arranquei à parede o desgraçado papel e desfiz em pedaços o esforço de tantos dias de perseverança e carinho. Quando os visitantes invadiram a sala, notaram na linha dos trabalhos suspensas duas enigmáticas pontas de papel rasgado. Estranhavam, ignorando que ali estava, interessante, em último capítulo, a história de uma cabra, de uma obra-prima que fora. As exposições artísticas eram dois em dois anos, alternadamente com as festas dos prêmios. Conseguia-se assim uma quantidade fabulosa de papel riscado para maior riqueza das galerias. Cobria-se o metim desde o soalho até o teto. Havia de tudo, não só desenhos. Alguns quadros a óleo, do Altino, risonhas aquarelas acidentando a monotonia cinzenta do Faber, do Conte, do fusain. Os futuros engenheiros aplicavam-se à aguadas de arquitetura, aos desenhos coloridos de máquinas. Entre as cabeças a crayon retinto, crinas de gineto, felpas de onagro lanzudo, inclinando o funil das orelhas, cerdosas frontes hirsutas de javali, que arreganhavam presas, perfis de audácia em colarinhos de renda, abdas atrevidas de feltro, plumas revoltadas, fisionomias de marujo, selvagens, arrepiadas, num sopro de borrasca, barbas incultas, carapuça esmurrada sobre a testa, cachimbo aos dentes; entre todas estas caras, avultava uma coleção notável de retratos do diretor. O melindroso assunto fora inventado pela gentileza de um antigo mestre. Preparou-se modelo; um aluno copiou com êxito; e depois, não houve mais desenhista amável que não entendesse dever

Revista Digital do LAV - Santa Maria - vol. 8, n. 2, p. 143 - 159. - mai./ago. 2015 ISSN 1983 - 7348 http://dx.doi.org/10.5902/1983734819869 
ensaiar-se na respeitável verônica. Santo Deus! Que ventas arranjavam ao pobre Aristarco! Era até $m$ esforço! Que olhos de blefarite! Que bocas de beiços pretos! Que calúnia de bigodes! Que invenção de expressões aparvalhadas para o digno rosto do nobre educador! Não obstante, Aristarco sentia-se lisonjeado pela invenção. Parecia-Ihe ter na face a cocegazinha sutil do crayon passando, brincando na ruga mole da pálpebra, dos pésde-galinha, contornando a concha da orelha, calcando a comissura dos lápis, entrevista na franja dos fios brancos, definindo a severa mandíbula barbeada, subindo pelas dobras oblíquas da pele ao nariz, varejando a pituitária, extorquindo um espirro agradável a desopilante. Por isso eram acatados os desenhistas de verônica. Os retratos todos, bons ou maus, eram alojados indistintamente nas molduras de recomendação. Passada a festa, Aristarco tomava ao quadro o desenho e levava para casa. Tinha-os já às resmas. Às vezes, em momentos de spleen, profundo spleen de grandes homens, desarrumava a pilha; forrava de retratos, mesas, cadeiras, pavimento. E vinhaIhe um êxtase de vaidade. Quantas gerações de discípulos the havia passado pela cara! Quantos afagos de bajulação a efígie de um homem eminente! Cada papel daqueles era um pedaço de ovação, um naco apoteose. E todas aquelas coisas feitas animavam-se e olhavam brilhantemente. "Vê, Aristarco, diziam em coro, vê, nós aqui somos tu, e nós to aplaudimos! " E Aristarco, como ninguém na terra, gozava a delícia inaudita, ele incomparável, único capaz de bem se compreender e de bem se admirar - de ver-se aplaudido em chusma por alter-egos, glorificado por uma multidão de si-mesmos. Primus inter pares. Todos, ele próprio, todos aclamando-o (POMPÉIA, s./d, 135138).

Contrários ao uso do desenho na escola como adorno cultural, alguns liberais a partir de 1870, e principalmente na década de 1880, defenderam a idéias de que uma educação popular para o trabalho deveria ser o principal objetivo do desenho na escola pública e iniciaram uma campanha para tornar o desenho obrigatório no ensino primário e secundário

O Estado se propunha dar um conhecimento técnico de desenho a todos os indivíduos de maneira que, libertados da ignorância, fossem capazes de produzir suas invenções. Educar o 'instituto da execução' para evitar que ele se tornasse um impedimento à objetivação da invenção era o princípio básico, isto é, primeiro aprender como 
trabalhar, depois aplicar as habilidades técnicas solucionando os problemas e dando forma concreta às criações individuais.

\section{Os liberais e o ensino anti-elitista do desenho.}

Em torno de 1870, um surto de desenvolvimento econômico propiciou alguma abertura na organização social e expansão de algumas idéias contestadoras. A criação do partido republicano naquele ano abriu uma fase de severas e sistemáticas críticas contra muitos aspectos da organização do império, incluindo a situação educacional.

Ao mesmo tempo, eram freqüentes os discursos feitos pelos abolicionistas acerca da necessidade de se estabelecer uma educação para o povo e para os escravos, demonstrando a preocupação com o seu futuro depois de libertos.

Os principais temas educacionais discutidos eram a alfabetização e a preparação para o trabalho. A necessidade de um ensino de desenho apropriado era referida como um importante aspecto da preparação para o trabalho industrial.

Na busca de um modelo que estabelecesse a união entre criação e técnica, isto é, entre arte e sua aplicação a indústria, os intelectuais e políticos (especialmente os liberais) brasileiros se comprometeram profundamente com os modelos da Walter Smith para o ensino da arte nos Estados Unidos que passaram a divulgar no Brasil.

Os principais divulgadores de Walter Smith no Brasil foram o jornal O Novo Mundo; Rui Barbosa (1941 e 1947), nos seus Pareceres sobre a reforma do ensino primário e secundário, e Abílio César Pereira Borges (1959) através de seu livro Geometria popular.

A popularização do ensino do desenho com aplicação à industria, era o objetivo da orientação que o inglês Walter Smith imprimia aos seus escritos e suas atividades como organizador do ensino da arte em Massachusetts (EUA). Influenciado pelas idéias de Redgrave e Dyce, de quem foi aluno na South Kensington School of Industrial Drawing and Crafts em Londres, da qual só resta hoje o Victoria and Albert Museum. Smith chegou a se demitir do cargo de professor da Leeds School of Art quando a

Revista Digital do LAV - Santa Maria - vol. 8, n. 2, p. 143 - 159. - mai./ago. 2015 ISSN 1983 - 7348 http://dx.doi.org/10.5902/1983734819869 
instituição (1868) começou a subverter os objetivos para os quais havia sido criada, ou seja, vincular a arte à educação popular, para enveredar pelo caminho do ensino da arte como verniz cultural obedecendo aos caprichosos desejos da classe média.

O Novo Mundo destacou em várias notícias e artigos o aspecto de democratização da arte que caracteriza a ação de Walter Smith em Massachusetts, para onde ele era contratado com carta branca para organizar o ensino das artes industriais.

Tinha O Novo Mundo grande importância cultural no Brasil daquela época. Trata-se de um jornal publicado por José Carlos Rodrigues, em Nova York (1872-1889) e escrito em Português.

Muitos dos mais importantes escritores brasileiros trabalharam neste periódico, como Machado de Assis e Sousândrade, que era também secretário do jornal.

O principal objetivo do jornal era vender produtos americanos e o american way of life no Brasil, apresentando as instituições sociais americanas como modelos para a sociedade brasileira.

A mais elogiada instituição americana era a educação. No campo da educação, foi dado especial relevo à divulgação da educação feminina e do desenho aplicado à industria.

Impregnado da moral protestante, apresentava a arte e o trabalho como veículo de educação e valorizava a educação para as artes industriais ao extremo.

André Rebouças escreveu para O Novo Mundo longos artigos defendendo a necessidade de se tornar compulsório, como Smith havia conseguido em Massachusetts, o ensino do desenho geométrico com aplicações à indústria.

Um número especial de $O$ Novo Mundo foi publicado acerca da Centennial Exhibition de 1876 em Filadélfia, onde se destacavam os trabalhos apresentados pela Escola Normal

Revista Digital do LAV - Santa Maria - vol. 8, n. 2, p. 143 - 159. - mai./ago. 2015 ISSN 1983 - 7348 http://dx.doi.org/10.5902/1983734819869 
de Artes, criada e dirigida por Smith, assim como os trabalhos de 24 cidades de Massachusetts, todas elas orientadas em seu ensino de arte por Smith.

O Novo Mundo em geral destacava a importância dada por Smith aos exercícios geométricos progressivos no ensino do desenho, sua idéia de que todo mundo tinha capacidade para desenhar e sua crença no ensino do desenho como veículo de popularização da arte através da adaptação a fins industriais, colaborando para a qualidade e prosperidade da produção industrial.

Rui Barbosa subscreveu as idéias de Smith nos Pareceres sobre a reforma da educação primária e secundária. Chegou mesmo a traduzir um longo texto do seu livro Art, education: scholastic and industrial (SMITH, 1872) que incluiu nos Pareceres como justificativa teórica para a supremacia que confere ao desenho em relação às outras disciplinas do currículo.

É ainda em Walter Smith que se baseou para traçar as recomendações metodológicas para o ensino do desenho.

Inspirado nas idéias defendidas por Rui Barbosa, o educador Abílio César Pereira Borges publicou uma Geometria popular que é uma espécie de sumário do Teacher's manual for free hand drawing de Walter Smith (1874).

O estudo propunha que o desenho começasse por linhas verticais, horizontais, oblíquas, paralelas, enfim, pelo que Smith, citado por Borges, chamava de alfabeto do desenho.

Seguia-se o estudo dos ângulos, triângulos, retângulos, numa gradação idêntica à proposta por Smith, acompanhando o traçado com definições geométricas como o próprio Smith recomendava. Seguiam-se ditados e exercícios de memória idênticos aos do livro de Smith.

Revista Digital do LAV - Santa Maria - vol. 8, n. 2, p. 143 - 159. - mai./ago. 2015 ISSN 1983 - 7348 http://dx.doi.org/10.5902/1983734819869 
Depois de estudar quadrados e polígonos, ele introduzia ornamentos e análises de folhas em superfície plana. Os exemplos botânicos eram organizados em forma de diagramas exatamente como o livro de Smith.

Ele ainda propunha o traçado de gregas, rosáceas, repetições verticais, repetições horizontais, formas entrelaçadas, seguindo mais uma vez Smith.

Alguns objetos simples (vasos de água, bacias etc.) tendo formas geométricas como Walter prescrevia, eram propostos para desenhar.

Finalmente, eram apresentados ornamentos e elementos arquitetônicos em diagrama (portais, arcos, colunas) de diferentes períodos, principalmente barrocos e neoclássicos. Os ornamentos como motivos para o trabalho em ferro eram também usados por Smith. Os elementos arquitetônicos não eram apresentados no seu manual, mas foram recomendados por ele no livro Art education: scholastic and industrial.

O livro de Abílio César Pereira Borges teve, no mínimo, 41 edições e foi usado em escolas pelo menos até 1959. O objetivo do livro, explicitado por ele próprio, era propagar o ensino do desenho geométrico e educar a nação para o trabalho industrial. Já os positivistas, atrelados ao evolucionismo, defendiam a idéia de que a capacidade imaginativa deveria ser desenvolvida na escola através do estudo e cópia dos ornatos, pois estes representavam a força imaginativa do homem em sua evolução a partir das idades primitivas.

No ensino do desenho, portanto, dominava o traçado de observação de modelos de ornatos em gesso. Recomendavam que se devia começar pelos baixos-relevos compostos por linhas retas, porque esta composição de ornatos era a mais sumária e correspondia à expressão ornamental dos povos primitivos da Oceania e África, para depois passar para os modelos em curvas e linhas caprichosas encontráveis na decoração de povos mais evoluídos, como os índios peruanos e mexicanos, e só então introduzir o alto-relevo representando figuras da fauna e da flora, expressão mais complexa, característica dos gregos no início de sua história.

Revista Digital do LAV - Santa Maria - vol. 8, n. 2, p. 143 - 159. - mai./ago. 2015 ISSN 1983 - 7348 http://dx.doi.org/10.5902/1983734819869 
Como os liberais haviam vencido a corrente positivista durante as lutas pela Reforma Republicana na Escola Nacional de Belas-Artes (1890), também eles conseguiram impor sua diretriz ao ensino de desenho na escola secundária através da reforma educacional de 1901, consubstanciada no Código Epitácio Pessoa.

Esta lei transcreve sucintamente as propostas de Rui Barbosa para o ensino do desenho, usando muitas vezes as mesmas palavras dos Pareceres.

É portanto o modelo de Walter Smith, cujos conteúdos já haviam entrado no circuito da educação brasileira através de Abílio César Pereira Borges, que a partir de então dominariam o currículo nos ginásios brasileiros. A preocupação social com o ensino do Desenho e da Arte nunca mais abandonou os arte/educadores e culminou no excelente trabalho da maioria das bem sucedidas ONGs que temos no Brasil e seguem a pedagogia freireana.

Os conteúdos de Walter Smith permaneceram quase imutáveis até 1958, atravessando várias reformas educacionais e ainda havia resquícios nas aulas de educação artística, designação que substituiu a disciplina de desenho nas escolas de Primeiro e Segundo Graus. Em quase todos os livros didáticos de educação artística para o $1^{\circ}$ grau, (Ensino Fundamental) editados nas décadas de 70 e 80 encontramos exercícios de gregas, rosáceas, frisas decorativas, ampliação de figuras, letras góticas, etc., remanescentes das propostas de Walter Smith, consagradas pelo Código Epitácio Pessoa e criados para preparar trabalhadores da indústria da construção civil. Podemos considerar esta espécie de ensino como a semente de uma educação para o design que não vingou, não se desenvolveu no mesmo compasso do desenvolvimento industrial do país. Ficou aderente ao primeiro surto industrial e foi suplantada pela livre expressão modernista.

É curioso que a aprendizagem destes elementos decorativos tinha sentido no início do século, já que se pretendia através do desenho preparar para o trabalho e a arquitetura era generosa na utilização de ornatos sobrepostos para cuja criação e

Revista Digital do LAV - Santa Maria - vol. 8, n. 2, p. 143 - 159. - mai./ago. 2015 ISSN 1983 - 7348 http://dx.doi.org/10.5902/1983734819869 
execução as rosáceas seriam exercício preparatório. Por outro lado, as paredes internas das casas ostentavam complicadas faixas decorativas em suas pinturas. Ainda mais, estes motivos eram também fartamente usados nas artes gráficas. Nos anos 70 e 80 não se justificava sua permanência como exercício escolar. As paredes do design decorativo eram de uma só cor e no máximo se pintava uma parede toda de cor diferente. Alguns dos exercícios propostos por Rui Barbosa resignificados voltaram não para a escola, mas para a Internet em sites de entretenimento para crianças e adultos. Vejam abaixo dois exemplos. Figura 1 e 2

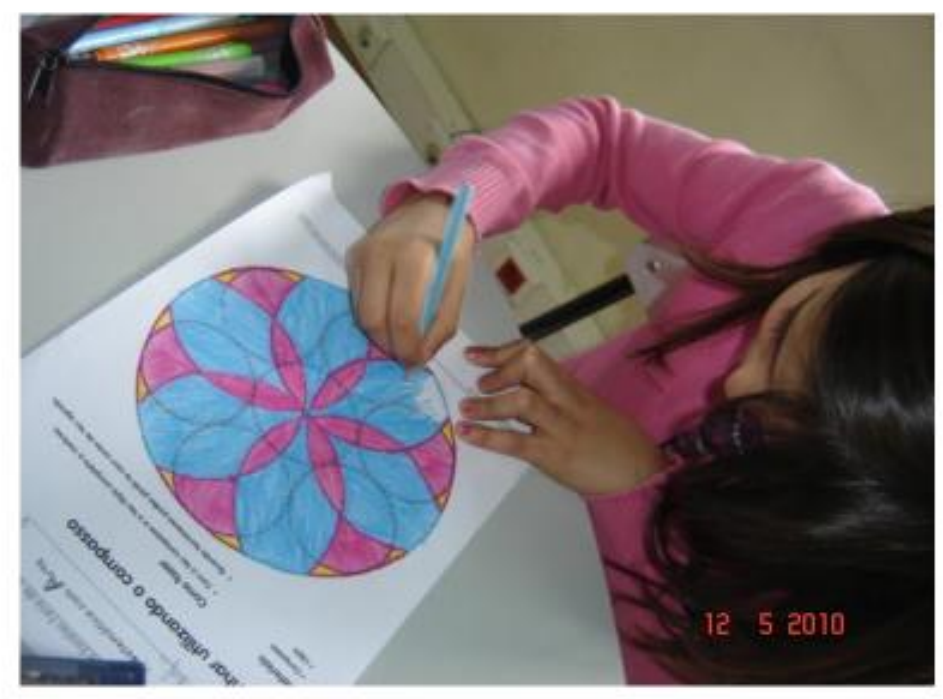

Figura 1:Fonte:http://www.pead.faced.br/sites/publico/eixo4/matematica/espaco_for ma/imagens/ atividade>. Acesso em: 10 jul. 2013. 


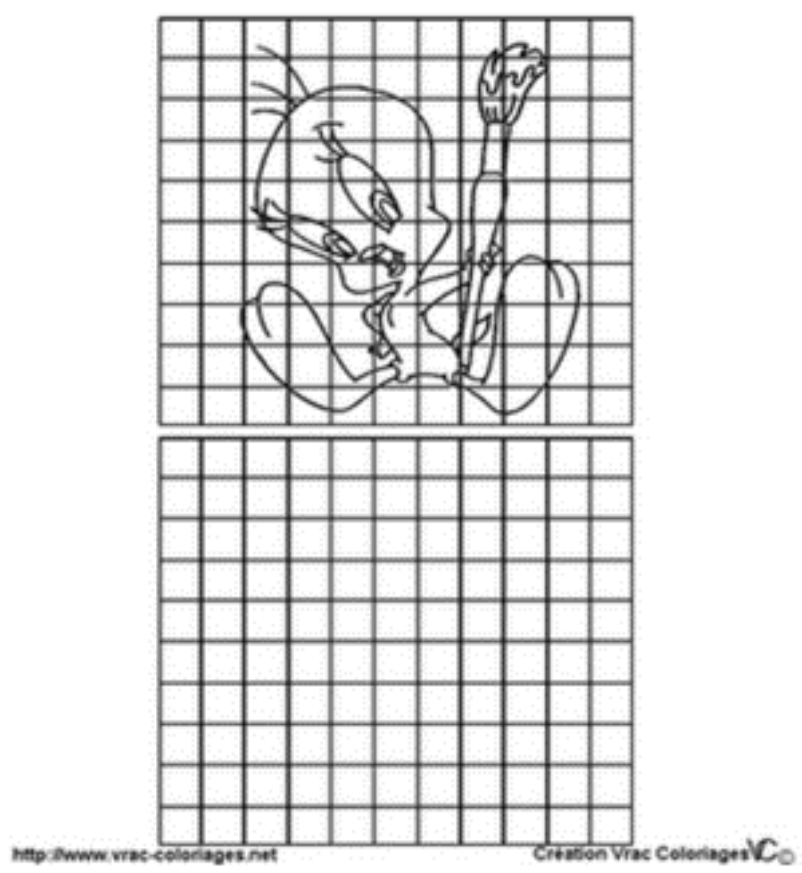

Figura2: Fonte: <http://www.vrac-coloriages.net>. Acesso em: 22 maio 2012.

Revista Digital do LAV - Santa Maria - vol. 8, n. 2, p. 143 - 159. - mai./ago. 2015 ISSN 1983 - 7348 http://dx.doi.org/10.5902/1983734819869 
Hoje há uma grande preocupação em promover a reconciliação da Arte e do Design na Educação, relação bem estabelecida na época da industrialização inglesa e americana. Deste tema falaram na Conferência Anual da National Art Education Association em Seattle, 2011 Kerry Freedman, Mary Ann Stankiewicz e Robin Vande Zander. Foi uma mesa excelente. Começou com a História do Ensino da Arte e do Design na Escola Normal de Massachusetts, hoje Massachusetts College of Art, onde eu fiz uma disciplina durante meu doutorado. Falaram de Walter Smith, que influenciou o mundo todo no início do século XX, da Nova Zelândia ao Brasil. Foi analisada também a Revista School Arts, por Robin Zander, demonstrando que esta preocupação com o Design sempre esteve subjacente ao ensino da Arte nos Estados Unidos. Tenho buscado provar através de pesquisas que no Brasil ${ }^{2}$ também foi assim, mas nem sempre. O modernismo nos afastou do Design. A frase com a qual Kerry Freedman, a

$2 \mathrm{O}$ (a) leitor(a) encontra na listagem abaixo uma série de outras fontes bibliográficas para aprofundamento de estudos sobre o período estudado:

BARBOSA, A. M. Teoria e prática da educação artística. São Paulo: Cultrix, 1975 BARBOSA, A. M. Arte educação no Brasil. São Paulo: Perspectiva, 1978.

BARBOSA, A. M. Arte-Educação: conflitos/acertos. São Paulo: Editora Max Limonad, 1984 BARBOSA, A.M História da Arte-Educação. (Org). São Paulo: Editora Max Limonad, 1986. BARBOSA, A. M. e SALES, H. (Org.) O Ensino da Arte e sua História. São Paulo: MAC-USP, 1990. BARBOSA, A. M. Ensino da arte: Memória e História. S. Paulo: Editora Perspectiva, 2005 BARBOSA, A. M.; FERRARA Lucrécia e Vernaschi E. (Org). O Ensino das Artes nas Universidades. São Paulo: EDUSP, 1993.

BARBOSA, A M. Redesenhando o Desenho: Educadores, Política e História. S. Paulo: Editora Cortez, 2015

BARBOSA, A. M. 'Walter Smiths Influence in Brazil And The Efforts By Brazilian Liberals To Overcome The Concept The Arts As An Elitist Activity'. In: Journal of Art And Design Education, 3(2), p.233-246, 1984.

BARBOSA, A. M. John Dewey e o ensino da Arte no Brasil. S. Paulo: Editora Cortez. 2001.

BARBOSA, R. Reforma do ensino secundário e superior (1882). Rio de Janeiro, Ministério da Educação e Saúde, 1941. Obras Completas, v.9, t.1.

BARBOSA, R. Reforma do ensino primário (1883). Rio de Janeiro. Ministério da Educação e Saúde, 1947. Obras Completas, v.10, t.1, 2, 3, 4.

BORGES, A. C. P. Geometria popular. Rio de Janeiro. Francisco Alves, 1959.

CARVALHO, B. A. Didática especial de desenho. São Paulo, Cia. Ed. Nacional, 1958.

ESPINHeIRA, A. Arte Popular e educação. São Paulo. São Paulo, Cia. Ed. Nacional,1938 FERRAZ, M. H. e FUSARI, M.F. A Arte na Educação Escolar. SP: Cortez, 1992.

GALVÃO, A. Subsídios para a história da Academia Imperial e da Escola Nacional de Belas Artes. S.n.t.

KUYUMJIAN, D. V. Arte infantil na escola primária. São Paulo, Ed. Clássico Científica, 1965.

PERRELET, L. A. O desenho a serviço da educação. Rio de Janeiro. Ed. Villas-Boas, 1930.

RABELO, S. Psicologia do desenho infantil. São Paulo, Cia Ed. Nacional, 1935.

SILVA, E. O desenho. Uberlândia, s. ed., 1958.

Revista Digital do LAV - Santa Maria - vol. 8, n. 2, p. 143 - 159. - mai./ago. 2015 ISSN 1983 - 7348

http://dx.doi.org/10.5902/1983734819869 
grande dama da Cultura Visual na Arte/Educação, terminou sua fala, ecoou por todo o Congresso todos os outros dias: "Art and Design Education is Visual Culture".

A África do Sul vem defendendo com grande ênfase Art e Design Education no currículo. Em um Congresso no Brasil sobre Design, organizado por Mônica Moura, na Universidade Anhembi Morumbi, um professor sul-africano disse que em sua universidade o número de professores de Design Education era quase o triplo do número de professores de outras áreas do Design. Quando perguntei por que, ele respondeu que era política do governo há muito tempo. Portanto, a nova onda em direção a integração do ensino da Arte e do Design não recomeçou apenas nos países ricos, mas é prioridade em um país em desenvolvimento também.

A crise econômica está obrigando todos os países a reverem suas posições e confiar no Design Thinking como uma metodologia que assegura boa produção. Mas, é preciso lembrar que Arte é a produção mais importante do ser humano.

Termino aqui meu argumento afirmando, em consonância com Kerry Freedman, que Design é Cultura Visual, ou melhor, é parte integrante dos Estudos Visuais que vêm expandindo o conceito de Arte.

\section{Referências}

BARBOSA, Rui, Reforma do ensino secundário e superior. Obras completas ( $1^{\text {a }}$ Ed. 1882). Rio de Janeiro, Ministério de Educação e Saúde, v.9, t2., 1941.

BARBOSA, Rui. Reforma do ensino primário. Obras completas (1a Ed. 1883). Rio de Janeiro, Ministério de Educação e Saúde, v.10, t4, 1947.

BORGES, Abilio Cesar Pereira. Geometria popular. $41^{\text {a }}$ Ed. Rio de Janeiro: Francisco Alves, 1959.

POMPÉIA, Raul. O Ateneu. São Paulo: Melhoramentos, s.d., p. 135-38.

Revista Digital do LAV - Santa Maria - vol. 8, n. 2, p. 143 - 159. - mai./ago. 2015 ISSN 1983 - 7348 http://dx.doi.org/10.5902/1983734819869 
SMITH, Walter. Art, education: scholastic and industrial. Boston: Osgood \& Co., 1872.

SMITH, Walter. Teachers's manual of freehand drawing. (1 ${ }^{\mathrm{a}} \mathrm{Ed} .1873$ ). Boston: Prang, 1874.

- Professora titular aposentada da Universidade de São Paulo e professora da Universidade Anhembi Morumbi. Tem experiência na área de Artes, com ênfase em Arte/Educação, atuando principalmente nos seguintes temas: Ensino da Arte e contextos metodológicos, História do Ensino da Arte e do Desenho, Ensino do Design, Administração de Arte, Multiculturalidade, Estudos de Museus de Arte e Estudos Visuais. E.mail: anamaebarbosa@gmail.com

Recebido em: 11 de maio de 2015.

Aprovado em: 23 de julho de 2015. 